\title{
Correction to: Therapeutic effects of probiotics on neurotoxicity induced by clindamycin and propionic acid in juvenile hamsters
}

\author{
Nora Al-Orf ${ }^{1,2} \cdot$ Afaf El-Ansary $^{3} \cdot$ Geir Bjørklund $^{4} \cdot$ Nadine Moubayed $^{5} \cdot$ Ramesa Shafi Bhat $^{1} \cdot$ Abir Ben Bacha ${ }^{1,6}$
}

Published online: 31 August 2018

(C) Springer Science+Business Media, LLC, part of Springer Nature 2018

Correction to: Metabolic Brain Disease.

https://doi.org/10.1007/s11011-018-0284-5

The original version of this article unfortunately contained a mistake. The family name of the fourth author listed in the title was incorrect, and the correct name is Nadine Moubayed, as noted in the addresses. Her name is now corrected in the author group of this article.

The original article has been corrected.

The online version of the original article can be found at https://doi.org/ 10.1007/s11011-018-0284-5

Geir Bjørklund

bjorklund@conem.org

1 Department of Biochemistry, College of Science, King Saud University, Riyadh, Saudi Arabia

2 The Materials Science Research Institute, King Abdulaziz City for Science and Technology, Riyadh, Saudi Arabia

3 Central Laboratory, King Saud University, Riyadh, Saudi Arabia

4 Council for Nutritional and Environmental Medicine, Toften 24, 8610 Mo i Rana, Norway

5 Department of Botany and Microbiology, College of Science, King Saud University, Riyadh, Saudi Arabia

6 Laboratory of Plant Biotechnology Applied to Crop Improvement, Faculty of Science of Sfax, University of Sfax, Sfax, Tunisia 